\title{
Total intravenous anaesthesia versus volatile induction and maintenance anaesthesia for controlled hypotension in lumbar spine fixation surgery: Comparative clinical study \\ Mohammed Mohammed Salah Eldin Shamloul, Ahmed Mohamed Abd-Elgaleel, Islam Essam Hosseiny Ibrahim Askar \\ Department of Anesthesiology and Intensive Care, Faculty of Medicine, Al-Azhar University
}

Corresponding author: Islam Essam Hosseiny Ibrahim Askar, Mobile: 01148636664; Email: islamaskar94@ gmail.com

\begin{abstract}
Background: Controlled hypotension during general anesthesia aims to lower the mean arterial blood pressure (MAP) to values between 55 and $65 \mathrm{mmHg}$ in patients with normal blood pressure, with the goal of significantly reducing blood loss by maintaining it at this level throughout the operation process. Controlled hypotension is frequently used for obtaining better exposure during spine surgery as small bleeding areas can produce better surgical field visibility and result in decreased time of surgery. Objective: This study was done to compare the efficacy and safety of TIVA and VIMA to induce hypotensive technique during spine surgery, with attention on the amount of blood loss, blood transfusion, hemodynamics, time of recovery and postoperative nausea and vomiting. Patients and Methods: This study included 40 patients of both sex, admitted for lumbar spine fixation surgery carried out at Al- Azhar University Hospitals (El-Hussein and Bab El-Sharia). They were randomly allocated into two equal groups, 20 patients each $(n=20)$ : Group I (TIVA); Total intravenous anaesthesia using (fentanyl and propofol). Group II (VIMA); Volatile induction and maintenance anesthesia (Inhalational anaesthesia) using (fentanyl and sevoflurane). Results: The following parameters were assessed between the 2 groups: Hemodynamics (HR, SBP, DBP and MAP), $\mathrm{SPO}_{2}$ and ET $\mathrm{CO}_{2}$ were continuously monitored and recorded at $15 \mathrm{~min}$ interval. Intraoperative blood loss, blood transfusion, duration of surgery, time of recovery and postoperative nausea and vomiting were monitored in all patients. Conclusion: this study showed that both TIVA and VIMA were effective in producing controlled hypotension for lumbar spinal fixation surgery. However, only TIVA was beneficial, allowing properly controlled hypotension, minimized intraoperative bleeding, and improved surgical field visibility compared to VIMA.
\end{abstract}

Keywords: Controlled hypotension, propofol, fentanyl, sevoflurane.

\section{INTRODUCTION}

Spinal fixation surgery may be associated with significant blood loss up to requiring transfusion of blood or its products ${ }^{(1)}$.

In the operations blood loss varies in volume depending on many factors including underlying pathology, patient's positioning and venous return affection ${ }^{(2)}$.

Maintaining a patient's hemodynamic stability and decrease in bleeding in the surgical field leading to highly surgeon satisfaction, also improve the results and outcome $^{(3)}$.

It also reduces the need for blood transfusion with its associated complications and the increase in consumption of financial resources ${ }^{(4)}$.

Permissive hypotension is one modality for reduction in bleeding during these surgeries, as this technique must be gradual and within limits where mean arterial blood pressure is achieving patient safety. Hypotensive technique was achieved by reducing both the peripheral vascular resistance with maintaining or slight decrease of the heart rate within safety margin ${ }^{(5)}$.

Total intravenous anaesthesia is used to achieve that (fentanyl with propofol), or inhalational anaesthesia by using fentanyl with an inhalational agent such as sevoflurane, isoflurane, or desflurane ${ }^{(6)}$.

\section{AIM OF THE WORK}

The aim of the present study was to compare between total intravenous anaesthesia (fentanyl with propofol) versus volatile induction and maintenance anaesthesia (fentanyl with sevoflurane) to induce permissive hypotension during spine surgery.

\section{Patients and Methods}


This prospective randomized clinical study was approved by the ethics committee in Al-Azhar University and patients' written informed consent was obtained.

The study was carried out at Al- Azhar University Hospitals (El-Hussein and Bab ElSharia).

Patients: This study included 40 patients of both sex, admitted for lumbar spine fixation surgery carried out at Al- Azhar University Hospitals (El-Hussein and Bab ElSharia). They were randomly allocated into two equal groups, 20 patients each $(n=20)$ : Group I (TIVA): Total intravenous anaesthesia using (fentanyl and propofol). Group II (VIMA): Volatile induction and maintenance anesthesia (Inhalational anaesthesia) using (fentanyl and sevoflurane).

Inclusion criteria: patients with American Society of Anesthesiologist (ASA) class I and II aged 25-60 years old of both sex undergoing lumbar spine fixation surgery. Time of operatione ranged frome 2-3 hours.

Exclusion criteria: ASA $\geq$ class III. Patients with a history of allergy to any of the medications used in the study. Body mass index (BMI) > 35. Patients with bleeding disorders. Patients on anticoagulant therapy or antiplatelets. Patients who when forced to use pharmacological drug as nitroglycerin to control hypertension occuring during operation were excluded. Time of operation not more than 3 hours.

Preoperative evaluation: The patients were screened for suitability by: History of previous complications from general anesthesia. Physical examination: chest, heart and abdominal examination. Investigations: complete blood picture, coagulation profile, and chest X-ray.

\section{Methods}

Group I (Received total intravenous anaesthesia): Two I.V. cannulas one in each arm was inserted, one for IV infusion pump and the other for IV fluid and induction of anaesthesia. All patients were pre-oxygenated via a face mask for 5 minutes prior to induction. The infusion line was attached to the intravenous cannula from the start, after administering fentanyl ( $1 \mathrm{mcg} / \mathrm{kg}$ i.v.). Anesthesia was induced with propofol 2 $\mathrm{mg} / \mathrm{kg}$. Then, after loss of the eyelash reflex, RESULTS administration of cisatracurium $0.15 \mathrm{mg} / \mathrm{kg} \mathrm{IV}$ was done followed by the intubation. Oxygen flow rate was adjusted to $3 \mathrm{~L} / \mathrm{min}$ and the controlled mechanical ventilation was started.

Anesthesia was maintained by continuous infusion of propofol at a rate of 12 $\mathrm{mg} / \mathrm{kg} / \mathrm{hr}$ for $10 \mathrm{~min}$ following the intubation, then $10 \mathrm{mg} / \mathrm{kg} / \mathrm{hr}$ for next $10 \mathrm{~min}$ and continued at $6-10 \mathrm{mg} / \mathrm{kg} / \mathrm{hr}$. The infusion rate was adjusted according to hemodynamic responses to maintain a mean arterial pressure (MAP) not below $35 \%$ of the base and fentanyl infusion at a rate of $0.1-0.5 \mu \mathrm{g} / \mathrm{kg} / \mathrm{h}$. Then, the patients were placed in the prone position.

Group II (Received an inhalational anaesthesia): All patients were pre-oxygenated via a facemask for 5 minutes prior to induction. The facemask was placed over the nose and mouth and while breathing 100\% oxygen from the breathing system, the patients were asked to take a deep breath and exhale to tidal volume with sevoflurane vaporizer that was on MAC $2 \mathrm{vol} \%$. The patients were asked to open their eyes every 3-5 seconds. At loss of the eyelash reflex, a bolus dose of fentanyl $1 \mu \mathrm{g} / \mathrm{kg}$, followed by cisatracurium $0.15 \mathrm{mg} / \mathrm{kg}$ then the intubation was done. Oxygen flow rate was adjusted to $3 \mathrm{~L} / \mathrm{min}$ and controlled mechanical ventilation was started. Anesthesia was maintained by Sevoflurane inhalation (2-4 vol\%). The concentration of sevoflurane was adjusted according to hemodynamic responses to maintain MAP not below $35 \%$ of the base. Fentanyl infusion was continued at a rate of $0.1-0.5 \mu \mathrm{g} / \mathrm{kg} / \mathrm{h}$. from the start in a separate IV line. Then, the patients were placed in the prone position.

\section{Data collection:}

Primary outcome: - Demographic data: (Age - Sex - BMI- ASA), hemodynamic data including heart rate, blood pressure (systolic, diastolic and mean blood pressure), oxygen saturation and ET $\mathrm{CO}_{2}$ were continuously monitored and recorded at 15 minutes intervals.

- Intraoperative blood loss.

- Duration of surgery.

- The need for blood transfusion.

Secondary outcome:

- Time of recovery.

- Post operative nausea and vomiting. 
Table (1): Comparison between groups according to duration of surgery (min).

\begin{tabular}{|l|c|c|c|c|}
\hline \multicolumn{1}{|c|}{ Duration (min) } & Group TIVA (N=20) & Group VIMA (N=20) & t-test & p-value \\
\hline Mean \pm SD & $152.30 \pm 5.11$ & $164.15 \pm 9.05$ & & \multirow{2}{*}{5.995} \\
\hline Range & $145-163$ & $145-180$ & $<0.001 * *$ \\
\hline
\end{tabular}

t-Independent Sample t-test; **p-value <0.001 HS

This table showed highly statistically significant difference between groups according to duration (min) with more decrease in TIVA group than VIMA group.

Table (2): Comparison between groups according to heart rate (Beat/min)

\begin{tabular}{|c|c|c|c|c|}
\hline Heart Rate (Beat/min) & $\begin{array}{c}\text { Group TIVA } \\
(\mathbf{N}=\mathbf{2 0})\end{array}$ & Group VIMA (N=20) & t-test & p-value \\
\hline \multicolumn{5}{|l|}{ Baseline } \\
\hline Mean \pm SD & $78.75 \pm 3.24$ & $80.10 \pm 3.11$ & \multirow{2}{*}{1.806} & \multirow{2}{*}{0.187} \\
\hline Range & $72-85$ & $75-85$ & & \\
\hline \multicolumn{3}{|l|}{ After induction } & \multirow{3}{*}{2.587} & \multirow{3}{*}{0.116} \\
\hline Mean \pm SD & $74.90 \pm 4.97$ & $77.00 \pm 3.06$ & & \\
\hline Range & $65-84$ & $72-83$ & & \\
\hline \multicolumn{3}{|l|}{ After 15 min } & \multirow{3}{*}{2.650} & \multirow{3}{*}{0.137} \\
\hline Mean \pm SD & $72.70 \pm 3.06$ & $74.60 \pm 2.48$ & & \\
\hline Range & $68-78$ & $70-80$ & & \\
\hline \multicolumn{3}{|l|}{ After 30 min } & \multirow{3}{*}{0.181} & \multirow{3}{*}{0.673} \\
\hline Mean \pm SD & $71.60 \pm 3.39$ & $72.00 \pm 2.49$ & & \\
\hline Range & $65-76$ & $68-78$ & & \\
\hline \multicolumn{3}{|l|}{ After $45 \mathrm{~min}$} & \multirow{3}{*}{1.777} & \multirow{3}{*}{0.190} \\
\hline Mean \pm SD & $68.85 \pm 3.65$ & $70.20 \pm 2.69$ & & \\
\hline Range & $65-75$ & $67-76$ & & \\
\hline \multicolumn{3}{|l|}{ After 60 min } & \multirow{3}{*}{2.351} & \multirow{3}{*}{0.075} \\
\hline Mean \pm SD & $66.25 \pm 3.55$ & $67.85 \pm 1.63$ & & \\
\hline Range & $60-72$ & $65-72$ & & \\
\hline \multicolumn{3}{|l|}{ After 75 min } & \multirow{3}{*}{0.468} & \multirow{3}{*}{0.498} \\
\hline Mean \pm SD & $64.80 \pm 3.52$ & $65.40 \pm 1.73$ & & \\
\hline Range & $60-70$ & $62-70$ & & \\
\hline \multicolumn{3}{|l|}{ After 90 min } & \multirow{3}{*}{1.485} & \multirow{3}{*}{0.106} \\
\hline Mean \pm SD & $63.35 \pm 2.60$ & $65.45 \pm 1.90$ & & \\
\hline Range & $60-68$ & $60-68$ & & \\
\hline \multicolumn{3}{|l|}{ After 105 min } & \multirow{3}{*}{1.714} & \multirow{3}{*}{0.103} \\
\hline Mean \pm SD & $62.10 \pm 1.97$ & $64.05 \pm 1.99$ & & \\
\hline Range & $60-65$ & $60-68$ & & \\
\hline \multicolumn{3}{|l|}{ After $120 \mathrm{~min}$} & & \\
\hline Mean \pm SD & $62.50 \pm 1.76$ & $63.05 \pm 1.70$ & 1009 & 0323 \\
\hline Range & $60-66$ & $60-67$ & & $0 . J 22$ \\
\hline After 135 min & & & & \\
\hline Mean \pm SD & $64.25 \pm 2.43$ & $65.65 \pm 1.53$ & 1765 & 0225 \\
\hline Range & $60-67$ & $64-70$ & 1.103 & 0.233 \\
\hline During closure of the skin & & & & \\
\hline Mean \pm SD & $73.28 \pm 1.63$ & $76.01 \pm 2.26$ & 1104 & 0261 \\
\hline Range & 70.7-76 & $72-82$ & 1.104 & 0.201 \\
\hline
\end{tabular}

t-Independent Sample t-test; $p$-value $>0.05 \mathrm{NS}$

This table showed no statistically significant difference between groups according to heart rate (Beat/min). 
Table (3): Comparison between groups according to mean arterial blood pressure ( $\mathrm{mmHg}$ ).

\begin{tabular}{|c|c|c|c|c|}
\hline $\begin{array}{l}\text { Mean Arterial Blood } \\
\text { Pressure (mmHg) }\end{array}$ & $\begin{array}{c}\text { Group TIVA } \\
(\mathrm{N}=20)\end{array}$ & $\begin{array}{c}\text { Group VIMA } \\
(\mathrm{N}=20)\end{array}$ & t-test & p-value \\
\hline Baseline & & & \multirow{3}{*}{0.673} & \multirow{3}{*}{0.417} \\
\hline Mean \pm SD & $94.90 \pm 4.83$ & $96.15 \pm 4.80$ & & \\
\hline Range & $88-104$ & $89-106$ & & \\
\hline \multicolumn{3}{|l|}{ After induction } & \multirow{3}{*}{2.693} & \multirow{3}{*}{0.089} \\
\hline Mean \pm SD & $88.14 \pm 4.65$ & $91.40 \pm 3.98$ & & \\
\hline Range & $80.3-97.4$ & $86-101$ & & \\
\hline \multicolumn{3}{|l|}{ After 15 min } & \multirow{3}{*}{2.147} & \multirow{3}{*}{0.071} \\
\hline Mean \pm SD & $83.77 \pm 3.22$ & $86.45 \pm 3.62$ & & \\
\hline Range & $79.2-90.2$ & $82-96$ & & \\
\hline \multicolumn{3}{|l|}{ After 30 min } & \multirow{3}{*}{2.417} & \multirow{3}{*}{0.115} \\
\hline Mean \pm SD & $75.77 \pm 2.14$ & $79.60 \pm 2.33$ & & \\
\hline Range & $70.7-79$ & $76-86$ & & \\
\hline \multicolumn{3}{|l|}{ After 45 min } & \multirow{3}{*}{1.638} & \multirow{3}{*}{0.359} \\
\hline Mean \pm SD & $71.99 \pm 2.47$ & $74.15 \pm 1.90$ & & \\
\hline Range & $67-76.2$ & $70-77$ & & \\
\hline \multicolumn{3}{|l|}{ After $60 \mathrm{~min}$} & \multirow{3}{*}{0.877} & \multirow{3}{*}{0.140} \\
\hline Mean \pm SD & $68.14 \pm 2.59$ & $70.40 \pm 1.39$ & & \\
\hline Range & $61.8-72.1$ & $68-73$ & & \\
\hline \multicolumn{3}{|l|}{ After 75 min } & \multirow{3}{*}{0.851} & \multirow{3}{*}{0.302} \\
\hline Mean \pm SD & $64.58 \pm 2.10$ & $67.30 \pm 1.95$ & & \\
\hline Range & $61.8-70$ & $64-72$ & & \\
\hline \multicolumn{3}{|l|}{ After 90 min } & \multirow{3}{*}{1.746} & \multirow{3}{*}{0.341} \\
\hline Mean \pm SD & $61.65 \pm 1.55$ & $63.00 \pm 1.52$ & & \\
\hline Range & $58.7-63.9$ & $61-68$ & & \\
\hline \multicolumn{3}{|l|}{ After 105 min } & \multirow{3}{*}{2.340} & \multirow{3}{*}{0.368} \\
\hline Mean \pm SD & $58.80 \pm 1.61$ & $60.10 \pm 1.21$ & & \\
\hline Range & $56-61$ & $58-62$ & & \\
\hline \multicolumn{3}{|l|}{ After $120 \mathrm{~min}$} & \multirow{3}{*}{1.929} & \\
\hline Mean \pm SD & $60.30 \pm 2.32$ & $62.10 \pm 1.07$ & & 0317 \\
\hline Range & $56-65$ & $60-64$ & & 0.311 \\
\hline After 135 min & & & & \\
\hline Mean \pm SD & $66.15 \pm 2.08$ & $67.40 \pm 2.33$ & 200 & 009 \\
\hline Range & $60-70$ & $63-73$ & 3.203 & 0.081 \\
\hline During closure of the skir & & & & \\
\hline Mean \pm SD & $85.66 \pm 3.04$ & $88.62 \pm 3.07$ & 242 & (104 \\
\hline Range & $81.9-91.7$ & $83.7-95.7$ & 2.432 & 0.104 \\
\hline
\end{tabular}

t-Independent Sample t-test; $p$-value >0.05 NS

This table showed no statistically significant difference between groups according to mean arterial blood pressure $(\mathrm{mmHg})$.

Table (4): Comparison between groups according to blood loss (ml) and number of patients need for blood transfusion.

\begin{tabular}{|c|c|c|c|c|}
\hline & Group TIVA $(\mathbf{N}=20)$ & Group VIMA ( $\mathbf{N = 2 0})$ & t/x2\# & p-value \\
\hline Blood loss (ml) & & & \multirow{3}{*}{14.734} & \multirow{3}{*}{$<0.001^{* *}$} \\
\hline Mean \pm SD & $497.00 \pm 81.89$ & $633.00 \pm 135.65$ & & \\
\hline Range & $400-700$ & $450-820$ & & \\
\hline $\begin{array}{l}\text { number of patients need for } \\
\text { blood transfusion }\end{array}$ & & & \multirow{3}{*}{ 4.286\# } & \multirow{3}{*}{$0.038^{*}$} \\
\hline No & $17(85.0 \%)$ & $11(55.0 \%)$ & & \\
\hline Yes & $3(15.0 \%)$ & $9(45.0 \%)$ & & \\
\hline
\end{tabular}


t-Independent Sample t-test; $x^{2}$ : Chi-square test

*p-value $<0.05 \mathrm{~S}$; **p-value $<0.001 \mathrm{HS}$

This table showed statistically significant difference between groups according to blood loss and blood transfusion that was less in TIVA.

Table (5): Comparison between groups according to the time of recovery (min).

\begin{tabular}{|c|c|c|c|c|}
\hline Recovery profile. & Group TIVA $(\mathbf{N}=20)$ & Group VIMA $(\mathrm{N}=\mathbf{2 0})$ & t-test & p-value \\
\hline Open eyes(Minutes) & & & \multirow{3}{*}{9.128} & \multirow{3}{*}{$0.004^{*}$} \\
\hline Mean \pm SD & $9.40 \pm 1.20$ & $8.38 \pm 0.93$ & & \\
\hline Range & $7-11$ & $7-10$ & & \\
\hline Verbal communication(M & & & \multirow{3}{*}{29.824} & \multirow{3}{*}{$<0.001 * *$} \\
\hline Mean \pm SD & $12.40 \pm 0.99$ & $10.58 \pm 1.12$ & & \\
\hline Range & $11-15$ & $9-13$ & & \\
\hline Mental orientation(Minut & & & \multirow{3}{*}{36.581} & \multirow{3}{*}{$<0.001^{* *}$} \\
\hline Mean \pm SD & $15.05 \pm 0.94$ & $13.15 \pm 1.04$ & & \\
\hline Range & $13-17$ & $12-15$ & & \\
\hline
\end{tabular}

t-Independent Sample t-test

*p-value $<0.05 \mathrm{~S}$; **p-value $<0.001 \mathrm{HS}$

This table showed statistically significant difference between groups according to the time of recovery with faster recovery in the Sevoflurane group.

Table (6): Comparison between groups according to postoperative nausea and vomiting.

\begin{tabular}{|l|c|c|c|c|}
\hline $\begin{array}{c}\text { Post Operative Nausea and } \\
\text { Vomiting }\end{array}$ & Group TIVA (N=20) & Group VIMA (N=20) & x2 & p-value \\
\hline No & $18(90 \%)$ & $14(70 \%)$ & \multirow{2}{*}{4.158} & $0.047 *$ \\
\hline
\end{tabular}

$x^{2}$ : Chi-square test; *p-value $<0.05 \mathrm{~S}$

This table showed statistically significant difference between groups according to postoperative nausea and vomiting.

\section{DISCUSSION}

Blood sparing in spine fixation surgery is important. Controlled hypotension is among the most widely used techniques for reducing blood loss.

Sevofluran-based inhalational anesthetic technique can be practiced wherever a general anesthetic is given. However, there is always a need to explore newer techniques and drugs to try and achieve better results and conditions for surgeries like spine surgery. One such technique that is gaining tremendous popularity for controlled hypotension is TIVA with propofol and opioids ${ }^{(7)}$.

This study was designed to evaluate TIVA with propofol and fentanyl and to determine whether better results and operative conditions can be achieved when compared to conventional sevoflurane-based inhalational anesthetic technique for permissive (controlled) hypotension.
The goal of a target mean blood pressure of $60-70 \mathrm{mmHg}$ was achieved in both groups.

In the present study, addition of fentanyl infusion to propofol infusion (group I) or sevoflurane inhalation (group II) was used for maintenance of anesthesia.

In our study, there were no statistically significant difference between the two groups in demographic data, including age, sex, BMI, ASA group.

At the same time, there were highly statistically significant difference between the two groups in the duration of surgery with more decrease in TIVA group than VIMA group.

According to hemodynamic parameters, It was found that, there were no statistically significant difference between the two groups in hemodynamics (systolic, 
diastolic, mean arterial pressure and heart rate), with slight decrease in TIVA group than VIMA group.

In the present study, the lower HR observed during TIVA requires careful interpretation because fentanyl had been infused continuously along with propofol. The lower heart rate might also because of opioids such as fentanyl. However, the infused fentanyl dose in both groups was the same, which suggests that the lower HR in TIVA group was related to propofol.

Both propofol and inhalation agents had a vasodilatory effect in a concentrationdependent manner. However, the extent of reflex tachycardia is quite variable. Compared to the apparent reflex tachycardia in isoflurane, sevoflurane usually does not alter the heart rate ${ }^{(8)}$. In contrast, propofol inhibits the baroreflex and can even result in bradycardia ${ }^{(9)}$. Therefore, propofol suppresses the cardiac output more than sevoflurane ${ }^{(10)}$. So in the patients did not have a cardiovascular disease and the MBP was controlled within the same range such as in the present study, the heart rate was lower in the TIVA than in the inhalational anaesthesia.

In terms of MAP, there was no significant difference between the two groups at the time points of intubation, the beginning of operation, during maintenance of anaesthesia, but TIVA provided a lower MAP than sevoflurane anaesthesia. This could be explained by the different effect of the two techniques on neuroendocrine stress.

TIVA and sevoflurane provided a similar depth of anaesthesia to maintain MAP at the same level, but because of stronger inhibition of the neuroendocrine reaction to stress by TIVA the MAP was lower with TIVA than with VIMA during operation ${ }^{(11)}$.

The present study aimed to evaluate the quality of the surgical field during spine surgery using TIVA compared to VIMA anaesthesia.

It was found that the amount of intraoperative bleeding that decreases field visibility was significantly lower with propofol infusion compared with sevoflurane inhalation at the same level of blood pressure. As fentanyl dose was adjusted in both groups to the same target blood pressure, it seemed that propofol reduced bleeding by another mechanism other than controlled hypotension.

Multiple experimental studies tried to explore such observation; they reported that, at clinically relevant concentrations, propofol did not influence the surface expression density of fibrinogen receptors, $\mathrm{P}$-selectin molecules, and the percentage of leukocyte-platelet aggregates ex vivo, thus did not allow interruption of either platelet or coagulation functions ${ }^{(12)}$.

Dordoni et al. ${ }^{(13)}$ found that propofol, in comparison with other anesthetics, had no effect on platelet function both ex vivo and in vitro and concluded that propofol might be considered as a hemostatically safe drug.

Recent experimental study supported the assumed hemostatic effect of propofol where Chung et al. ${ }^{(14)}$ suggested that propofol at concentrations required for sedation and general anesthesia had no inhibitory effect on platelet aggregation after $3 \mathrm{~h}$ of incubation.

In support of the obtained results and these experimental explanations, clinical trials reported similar reduction in amount of bleeding during various surgical procedures using propofol. Albertin et al. ${ }^{(15)}$ compared the effects of sevoflurane and propofol on lumbar-paraspinal-muscles regional blood flow, as well as on bleeding when controlled hypotension was used. They found that peripheral blood flow was significantly greater in the propofol group both before and during the hypotensive period, but blood loss and intraoperative bleeding were significantly reduced when propofol had been used. They explained these findings hypothesizing a selective vasodilation by propofol (postcapillary venous vasodilation), different from that by sevoflurane (precapillary arteriolar vasodilation).

In the case of a comparison between sevoflurane and propofol anaesthesia, study done by Wormald et al. $^{\left({ }^{(16)}\right.}$ showed less blood loss or a better surgical score in patients given propofol than those given sevoflurane. However, Manola et al. ${ }^{(17)}$ reported a similar surgical score and blood loss between propofol and sevoflurane, which was superior to isoflurane.

The patient's orientation with respect to time and place provides a rough estimation of the recovery of cognitive function. In our 
study, the recovery profile showed a statistically significant difference between the two groups, with faster recovery in the Sevoflurane group.

Our results were similar to a study done by Orhon et al. ${ }^{(18)}$ and Kumar et al. ${ }^{(19)}$ who also found that recovery time after Sevoflurane anaesthesia was shorter than with Propofol based anaesthesia.

Shah and Adaroja ${ }^{(20)}$ compared the emergence and post operative recovery profile between Sevoflurane and Propofol. They found that Sevoflurane has a better recovery profile than the intravenous Propofol. This effect of Sevoflurane was attributed to its insoluble nature, rapid wash in and out and low blood gas partition coefficient, all of which led to the rapid emergence.

The results of this study are in agreement with Castagnini et al. (21) who studied the differences between sevoflurane and propofol regarding recovery criteria in the neuroradiological procedures and found that use of sevoflurane for maintenance of anesthesia for prolonged neurosurgical procedures was associated with more rapid recovery than propofol.

On the other hand, this study was inconsistent with study done by Sneyd $\boldsymbol{e t} \boldsymbol{a l}$. (22). They found that both sevoflurane and propofol in combination with remifentanil, were satisfactory agents for maintenance of anesthesia in neurosurgical patients and the differences in the recovery times were not clinically significant.

According to Postoperative nausea and vomiting. In our study, there was a statistically significant difference between the two groups. In a review of early postoperative complications following neurosurgical procedures, PONV was the commonest complication (38.7\%), although the anesthesia technique was not mentioned in that study of Gan et al. ${ }^{(23)}$.

In the present study six patients $(30 \%)$ from VIMA group developed nausea and vomiting in the post-operative period, while only two patients in TIVA group (10\%) had nausea and vomiting.

The postulated mechanisms of propofol antiemetic effect may include antidopaminergic activity, depressant effect on the chemoreceptor trigger zone and vagal nuclei, decreased release of glutamate and aspartate in the olfactory cortex and reduction of serotonin concentrations in the area postrema ${ }^{(24)}$.

The results of this study were in line with the results of Gupta et al. ${ }^{(25)}$ who reported that TIVA with propofol had been found by to produce less PONV compared to inhalational anesthesia in non-neurosurgical patients.

\section{CONCLUSION}

This study showed that both TIVA and VIMA were effective in producing controlled hypotension for lumbar spinal fixation surgery. However, only TIVA was beneficial, allowing properly controlled hypotension, minimized intraoperative bleeding, and improved surgical field visibility compared to VIMA. Regarding the recovery criteria, VIMA group provided faster recovery than TIVA group. Regarding postoperative nausea and vomiting, TIVA group significantly reduced the incidence of postoperative nausea and vomiting, in the early recovery period than VIMA group.

\section{REFERENCES}

1. Cole JW, Murray DJ, Snider RJ et al. (2005): Aprotinin reduces blood loss during spinal surgery, in children. Spine, 28: 2482-2485.

2. Lee TC, Yang LC, Chen HJ (2007): Effect of patient's position and hypotensive anesthesia on inferior vena caval pressure, Spine, 23: 941-947.

3. Szpalski M, Gunzburg R, Sztern B (2004): An overview of blood-sparing techniques used in spine surgery during the perioperative period. European Spine Journal, 13 (1): S18-27.

4. Paul GE, Ling E, Lalonde C, Thabene L (2007): Deliberate hypotension in orthopedic surgery reduces blood loss and transfusion requirements: a metaanalysis of randomized controlled trials. Can J Anaesth, 54:798-810.

5. Goma HM, Sharrock NE, Gökçe BM et al. (2012): Comparison between prostaglandin E1, and esmolol infusions in controlled hypotension during scoliosis correction surgery a clinical trial. Middle East J Anaesthesiol., 21:599-604. 
6. Degoute CS (2007): Controlled hypotension: a guide to drug choice. Drugs, 67 (7): 1053-1076.

7. Ankichetty SP, Ponniah M, Cherian V et al. (2011): Comparison of total intravenous anesthesia using propofol and inhalational anesthesia using sevoflurane for controlled hypotension in spine surgery. J Anaesthesiol Clin Pharmacol., 27(3):328-32.

8. Pagel $\mathrm{P}$, Kersten $\mathrm{J}$, Farber $\mathrm{N}$ et al. (2005): Cardiovascular pharmacology. In: Miller RD, ed. Miller's Anesthesia. Philadelphia: Elsevier Churchill Livingstone.

9. Reves J, Glass P, Lubarsky D et al. (2005): Intravenous nonopioid anesthetics. In: Miller RD, ed., Miller's Anesthesia, Philadelphia; Elsevier Churchill Livingstone.

10. Husedzinovic I, Tonkovic D, Barisin S et al. (2003): Hemodynamic differences in sevoflurane versus propofol anesthesia. Coll Antropol., 27: 205-12.

11. Ledowski T, Bein B, Hanss R (2005): Neuroendocrine stress response and heart rate variability: a comparison of total intravenous versus balanced anesthesia. Anesth Analg., 101: 17001705.

12. Scheinichen D, Bornscheuer A, Jaeger $\mathrm{K}$ et al. (2002). Influence of a bolus injection of thiopental and propofol on the expression density of P-selectin and fibrinogen receptors on the surface of human platelets ex vivo. Anasthesiol Intensivmed Notfallmed Schmerzther, 37: 403-408.

13. Dordoni PL, Frassanito L, Bruno MF et al. (2004): In vivo and in vitro effects of different anesthetics on platelet function. Br J Haematol., 125: 79-82.

14. Chung HG, Myung SA, Son HS et al. (2013): In vitro effect of clinical propofol concentrations on platelet aggregation. Artif Organs, 37: 51-55.

15. Albertin A, La Colla L, Gandolfi A et al. (2008): Greater peripheral blood flow but less bleeding with propofol versus sevoflurane during spine surgery: a possible physiologic model? Spine, 33 (18): 2017-2022.
16. Wormald PJ, van Renen G, Perks J et al. (2005): The effect of the total intravenous anesthesia compared with inhalational anesthesia on the surgical field during endoscopic sinus surgery. Am J Rhinol., 19: 514-20

17. Manola M, De Luca E, Moscillo L (2005): Using remifentanil and sufentanil in functional endoscopic sinus surgery to improve surgical conditions. ORL J Otorhinolaryngol Relat Spec., 67: 83-6.

18. Orhon ZN, Devrim S, Celik M (2013): Comparison of recovery profiles of Propofol and Sevoflurane anesthesia with bispectral index monitoring in percutaneous nephrolithotomy. Korean J Anesthesiol., 64 (3): 223 - 228.

19. Kumar A, Vasanthan MR, Kannan $N$ (2013): Comparison of recovery from Propofol TIVA and Sevoflurane VIMA in day case surgeries. Journal of pharmaceutical and biomedical sciences, 31 (31): 1214-20.

20. Shah A, Adaroja RN (2011): Comparison of haemodynamic changes with Propofol and Sevoflurane anaesthesia during laparoscopic surgery.National journal of medical research, 1 (2): $76-79$.

21. Castagnini HE, Van Eijs F, Salevsky FC et al. (2004): Sevoflurane for interventional neuroradiology procedure is associated with more rapid early recovery than propofol. Can J Anesth., 51: 5:486-491.

22. Sneyd JR, Andrew CJ, Tsubokawa T (2005): Comparison of propofol/ remifentanyl and sevoflurane/remifentanyl for maintenance of anesthesia for elective intracranial surgery. Br J Anesth., 94: 778-783.

23. Gan T, Meyet T, Apfel C et al. (2003): Consensus guidelines for managing postoperative nausea and vomiting. Anesth Analg., 97 (1): 62-71.

24. Jen WC and Paul FW (2001): Propofol antiemetic properties. Nonopioid Intravenous Anesthesia. Clinical Anesthesia; 4th edition. Churchil Livingstone. New York, Chapter 13. 
Mohammed Shamloul et al.

25. Gupta A, Stierer T, Zuckerman $R$ (2004): Comparison of recovery profile after ambulatory anesthesia with propofol, isoflurane, sevoflurane and desflurane: a systematic review. Anesth Analg., 98 (3): 632-641. 